\title{
Incorporation of globally available datasets into the roving cosmic-ray neutron probe method for estimating field-scale soil water content
}

\author{
William Alexander Avery ${ }^{1}$, Catherine Finkenbiner ${ }^{1}$, Trenton E. Franz ${ }^{1}$, Tiejun Wang ${ }^{1}$, Anthony L. Nguy-Robertson ${ }^{1}$, \\ Andrew Suyker ${ }^{1}$, Timothy Arkebauer ${ }^{1,2}$, and Francisco Muñoz-Arriola ${ }^{1,3}$ \\ ${ }^{1}$ School of Natural Resources, University of Nebraska-Lincoln, Lincoln, NE 68588, USA \\ ${ }^{2}$ Department of Agronomy and Horticulture, University of Nebraska-Lincoln, Lincoln, NE 68588, USA \\ ${ }^{3}$ Biological Systems Engineering, University of Nebraska-Lincoln, Lincoln, NE 68588, USA
}

Correspondence to: Trenton E. Franz (tfranz2@unl.edu)

Received: 23 February 2016 - Published in Hydrol. Earth Syst. Sci. Discuss.: 2 March 2016

Revised: 15 July 2016 - Accepted: 5 September 2016 - Published: 19 September 2016

\begin{abstract}
The need for accurate, real-time, reliable, and multi-scale soil water content (SWC) monitoring is critical for a multitude of scientific disciplines trying to understand and predict the Earth's terrestrial energy, water, and nutrient cycles. One promising technique to help meet this demand is fixed and roving cosmic-ray neutron probes (CRNPs). However, the relationship between observed low-energy neutrons and SWC is affected by local soil and vegetation calibration parameters. This effect may be accounted for by a calibration equation based on local soil type and the amount of vegetation. However, determining the calibration parameters for this equation is labor- and time-intensive, thus limiting the full potential of the roving CRNP in large surveys and long transects, or its use in novel environments. In this work, our objective is to develop and test the accuracy of globally available datasets (clay weight percent, soil bulk density, and soil organic carbon) to support the operability of the roving CRNP. Here, we develop a $1 \mathrm{~km}$ product of soil lattice water over the continental United States (CONUS) using a database of in situ calibration samples and globally available soil taxonomy and soil texture data. We then test the accuracy of the global dataset in the CONUS using comparisons from 61 in situ samples of clay percent $\left(\mathrm{RMSE}=5.45 \mathrm{wt} \%, R^{2}=0.68\right)$, soil bulk density $\left(\mathrm{RMSE}=0.173 \mathrm{~g} \mathrm{~cm}^{-3}, R^{2}=0.203\right)$, and soil organic carbon $\left(\mathrm{RMSE}=1.47 \mathrm{wt} \%, R^{2}=0.175\right)$. Next, we conduct an uncertainty analysis of the global soil calibration parameters using a Monte Carlo error propagation analysis (maximum
\end{abstract}

RMSE $\sim 0.035 \mathrm{~cm}^{3} \mathrm{~cm}^{-3}$ at a $S W C=0.40 \mathrm{~cm}^{3} \mathrm{~cm}^{-3}$ ). In terms of vegetation, fast-growing crops (i.e., maize and soybeans), grasslands, and forests contribute to the CRNP signal primarily through the water within their biomass and this signal must be accounted for accurate estimation of SWC. We estimated the biomass water signal by using a vegetation index derived from MODIS imagery as a proxy for standing wet biomass (RMSE $<1 \mathrm{~kg} \mathrm{~m}^{-2}$ ). Lastly, we make recommendations on the design and validation of future roving CRNP experiments.

\section{Introduction}

By the year 2050, over 9 billion people are predicted to inhabit the Earth (United Nations, 2015). The monumental task of feeding the projected global population will require a near doubling of grain production (FAO, 2009). As of today, the majority $(\sim 2 / 3)$ of water consumption by humans is used for agriculture, where approximately half of all global food production comes from irrigated agriculture (Mekonnen and Hoekstra, 2011). As such, an increase in food demand will put an even greater demand on freshwater resources, particularly an increasing reliance on groundwater (Mekonnen and Hoekstra, 2011). The ability to model and forecast the hydrologic cycle will continue to play a major role in effective water resource management in the coming decades. Currently, most land surface models (LSMs) aimed at characterizing the 
fluxes of water, energy, and nutrients have relied on either sparse point-scale soil water content (SWC) monitoring networks (Crow et al., 2012) or remote sensing products with large pixel sizes $(\sim 36 \mathrm{~km})$ and shallow penetration depths (Kerr et al., 2010; Entekhabi et al., 2010). A critical scale gap exists between these methods, requiring innovative monitoring strategies (Robinson et al., 2008). Moreover, as LSMs continue to move towards highly refined spatial resolutions of $1 \mathrm{~km}$ or less (Wood et al., 2011), the need for accurate and spatially exhaustive SWC datasets continues to grow (Beven and Cloke, 2012).

Estimating and monitoring SWC at the appropriate spatial and temporal scale for effective incorporation into LSMs has proven to be a difficult task. On the one hand, monitoring networks at the regional (e.g., Nebraska Automated Weather Data Network; AWDN, Oklahoma Mesonet) and continental scales (Climate Reference Network; CRN, Soil Climate Analysis Network; SCAN) have continuously recording point sensors. However, these sparse networks are difficult to place in the context of the surrounding landscape given the multifractal behavior that soil moisture fields exhibit (Korres et al., 2015). Techniques such as temporal stability analysis (Vachaud et al., 1985) can help improve the representativeness of the monitoring networks but require a priori spatial information. On the other hand, remote sensing satellites using passive microwaves can monitor global SWC data every few days, albeit with large spatial footprints ( $~ 36$ by $36 \mathrm{~km}$; Entekhabi et al., 2010; Kerr et al., 2010). In addition, passive microwaves lack significant penetration depths ( $\sim 2-5 \mathrm{~cm}$; Njoku and Entekhabi, 1996), limiting their effectiveness as a remote sensing input for full root zone coverage in LSMs.

Alternatively, the field of geophysics offers a variety of techniques to help fill the spatial and temporal gaps between point sensors and remote sensing products (Bogena et al., 2015). Bridging this gap requires both novel geophysical techniques and integrated modeling strategies capable of merging both point and remotely sensed data into a unified framework (Binley et al., 2015). One promising geophysical technique to help fill this need is fixed (Desilets et al., 2010; Zreda et al., 2012) and roving cosmic-ray neutron probes (CRNPs; Chrisman and Zreda, 2013; Dong et al., 2014), which measure the ambient amount of low-energy neutrons in the air. The low-energy neutrons are highly sensitive to the mass of hydrogen, and thus SWC, in the near surface (Zreda et al., 2012). CRNPs estimate the area-averaged SWC because neutrons are well mixed within the footprint of the sensor, which typically has a radius of several hundred meters and depths of tens of decimeters (Desilets and Zreda, 2013; Köhli et al., 2015).

To date, the CRNP method has been mostly used as a fixed system in one location to continuously measure SWC as part of a large monitoring network (Zreda et al., 2012; Hawdon et al., 2014). Recent advancements have allowed the CRNP to be used in mobile systems to monitor transects across Hawaii
(Desilets et al., 2010), monitor entire basins in southern Arizona (Chrisman and Zreda, 2013), compare against remote sensing products in central Oklahoma (Dong et al., 2014), and monitor $\sim 140$ agricultural fields in eastern Nebraska (Franz et al., 2015). In order to accurately estimate SWC, the CRNP method relies on a calibration function to convert observed low-energy neutron counts into SWC (Desilets et al., 2010; Bogena et al., 2013; see Sect. 2.2 for full details). The calibration procedure requires site-specific sampling of both soil and vegetation data in order to determine the required parameters. While the calibration of a fixed CRNP is fairly standardized (Zreda et al., 2012; Franz et al., 2012; Iwema et al., 2015; Baatz et al., 2014), the heterogeneous nature of soil and vegetation characteristics across a landscape makes the pragmatic calibration of the roving CRNP a significant challenge. Specifically, the presence of water within vegetation and the soil minerals may alter the shape of the local calibration function and thus accuracy of SWC (Baatz et al., 2015). The need for reliable, accurate, depth-dependent, and localized soil and vegetation spatial information for use in the calibration function is critical in order to fully exploit the potential of the roving CRNP to monitor landscape-scale SWC across the globe.

The objective of this study is to explore the utility and accuracy of currently available global soil and vegetation datasets (soil organic carbon, soil bulk density, soil clay weight percent, and crop biomass) for use in the calibration function. To accomplish our objective, we aimed to answer the following questions:

1. Can global datasets of soil bulk density, soil organic carbon, and soil clay weight percent be used instead of in situ sampling within reasonable error for use in the roving CRNP calibration function?

2. Can the use of remotely sensed vegetation products, specifically the Green Wide Dynamic Range Vegetation Index (GrWDRVI) be used to quantify fresh biomass with reasonably low error $\left(<1 \mathrm{~kg} \mathrm{~m}^{-2}\right)$ for use in the roving CRNP calibration function?

To answer these questions, we tested the accuracy of these datasets against in situ sample datasets of the same parameters. Existing in situ datasets from across the continental United States (CONUS) were combined with in situ datasets from eastern Nebraska, which focused on fast-growing crops of maize and soybean. Specifically, we tested the accuracy and use of a $\sim 1 \mathrm{~km}$ global soil dataset (Shangguan et al., 2014). In addition, we examined the use of the GrWDRVI (Gietelson, 2004) derived from NASA's MODIS sensor aboard the Terra satellite for use in estimating the amount of fresh crop biomass.

The remainder of the paper is organized as follows: in the Methods section, the CRNP method is first presented, with emphasis on the integration of the calibration function and soil and vegetation parameters to convert observed low- 
energy neutron counts into SWC. Next, in situ methods for estimating the soil and vegetation calibration parameters are discussed, which is followed by discussions on the soil and vegetation products available globally at $\sim 1 \mathrm{~km}$ resolution. In the Results section, we first compare the in situ soil sampling against the global datasets. Next, we develop a $1 \mathrm{~km}$ CONUS soil lattice water map using in situ samples. We then compare the GrWDRVI against in situ samples from Nebraska to estimate the changes in maize and soybean fresh biomass. Lastly, we present an error propagation analysis investigating the potential uncertainty of using the global soil calibration data vs. local in situ sampling. The paper concludes with a discussion on best-practice recommendations for calibrating and validating a roving CRNP experiment.

\section{Methods}

\subsection{Overview of cosmic-ray neutron probe}

The CRNP estimates area-averaged SWC via measuring the intensity of low-energy neutrons (i.e., $\sim$ epithermal) near the ground surface (Zreda et al., 2008, 2012). A cascade of neutrons with a continuous energy spectrum are created in the Earth's atmosphere when incoming higher-energy particles produced within supernovae interact with atmospheric nuclei (Zreda et al., 2012 and Köhli et al., 2015). After fast neutrons are created, they continue to lose energy during numerous collisions with nuclei in air and soil and become low-energy neutrons that are detected with the probe. The abundance of hydrogen atoms in the air and soil largely controls the removal rate of low-energy neutrons from the system (Zreda et al., 2012). Water in the near-surface soil (i.e., SWC) is one of the largest sources of hydrogen present in terrestrial systems (McJannet et al., 2014). Thus, relative changes in the intensity of low-energy neutrons are overwhelmingly due to changes in the SWC. However, the shape of the calibration function (see Sect. 2.2) is somewhat modified by local soil and vegetation parameters (Zreda et al., 2012) reflecting the variation of background hydrogen levels across landscapes.

Using a standard neutron detector with a $2.54 \mathrm{~cm}$ layer of plastic, Zreda et al. (2008) first described the support volume the detector measures to be a circle of $\sim 300 \mathrm{~m}$ in radius with vertical penetration depths of 12 to $76 \mathrm{~cm}$ depending on SWC. Recent neutron transport modeling has further refined the footprint area to be a function of atmospheric water vapor, elevation (Desilets and Zreda, 2013), surface heterogeneity (Köhli et al., 2015), vegetation (Köhli et al., 2015), and SWC (Köhli et al., 2015). Köhli et al. (2015) found the footprint to range between 130 and $240 \mathrm{~m}$ in radius depending on conditions. Despite the varying footprint characteristics, the large measurement area of tens of hectares makes this non-invasive technique an ideal complement to long-term surface energy balance monitoring around the globe. Currently, there are $>200$ fixed CRNP (personal communication with Darin De- silets of HydroInnova LLC, Albuquerque, NM, 2015) functioning in this capacity around the United States (Zreda et al., 2012), Australia (Hawdon et al., 2014), Germany (Baatz et al., 2014), South Africa, China, and the United Kingdom. The real-time SWC data provide critical infrastructure for use in weather forecasting and data assimilation in LSMs (Shuttleworth et al., 2013; Rosolem et al., 2014; Renzullo et al., 2014).

In addition to the fixed CRNP measuring hourly SWC, a roving version of the CRNP has been used to reliably measure SWC at temporal resolutions as low as $1 \mathrm{~min}$ (Chrisman and Zreda, 2013; Dong et al., 2014) providing the ability to make SWC maps over hundreds of square kilometers in a single day. Moreover, Franz et al. (2015) found that a combination of fixed and roving CRNP data in a statistical framework has the ability to form an accurate, real-time, and multiscale monitoring network. With the continued increase in observation spatial scales, the use of in situ sampling in the traditional CRNP calibration procedure is no longer practical, thus requiring the use of alternative available datasets to improve its operability. The remainder of this work will first describe the availability of such global datasets and then test the accuracy of using the datasets in the CRNP calibration function.

\subsection{The cosmic-ray neutron probe calibration function}

In order to convert observed low-energy neutron measurements into SWC, a series of scaling factors, correction factors, and calibration functions have been developed. Zreda et al. (2012) describe in detail the effects from changes in geomagnetic latitude, changes in incoming high-energy cosmic-ray intensity, and atmospheric pressure. Rosolem et al. (2013) further describe changes in absolute air humidity near the surface. Following these four scaling and correction factors, the corrected low-energy neutron counts can be converted into SWC. Desilets et al. (2010) proposed the original calibration function (Eq. 1) valid for mass-based gravimetric measurements, which Bogena et al. (2013) further expanded for volumetric water content. The calibration function has been successfully tested against direct sampling and point sensor measurements with RMSE $<0.03 \mathrm{~cm}^{3} \mathrm{~cm}^{-3}$ across the globe including arid shrublands in Arizona, USA (Franz et al., 2012), semi-arid forests in Utah, USA (Lv et al., 2014), to humid forests in Germany (Bogena et al., 2013), and across ecosystems in Australia (Hawdon et al., 2014). The original calibration function proposed by Desilets et al. (2010) is

$\theta_{\mathrm{T}}=\left(\frac{a_{0}}{\frac{N}{N_{0}}-a_{1}}-a_{2}\right)$,

where $\theta_{\mathrm{T}}\left(\mathrm{g} \mathrm{g}^{-1}\right)$ is the total gravimetric water content, $a_{0}=0.0808, a_{1}=0.3720, a_{2}=0.1150$ (see Desilets et al., 2010 , for details), $N$ (counts per time interval) is the afore- 
mentioned low-energy corrected neutron count rate, and $N_{0}$ (counts per time interval) is the theoretical counting rate at a location with dry silica soils. Zreda et al. (2012) illustrated that

$\theta_{\mathrm{T}}=\theta_{\mathrm{p}}+\theta_{\mathrm{LW}}+\theta_{\mathrm{SOC}}$,

where $\theta_{\mathrm{p}}\left(\mathrm{g} \mathrm{g}^{-1}\right)$ is the gravimetric pore water content in the soil, $\theta_{\mathrm{LW}}\left(\mathrm{g} \mathrm{g}^{-1}\right)$ is the soil lattice water, and $\theta_{\mathrm{SOC}}\left(\mathrm{g} \mathrm{g}^{-1}\right)$ is the soil organic carbon water equivalent. The volumetric SWC $\left(\mathrm{cm}^{3} \mathrm{~cm}^{-3}\right)$ is found by multiplying $\theta_{\mathrm{p}}$ by $\frac{\rho_{\mathrm{b}}}{\rho_{\mathrm{w}}}$, where $\rho_{\mathrm{b}}\left(\mathrm{g} \mathrm{cm}^{-3}\right)$ is dry soil bulk density and $\rho_{\mathrm{w}}=1 \mathrm{~g} \mathrm{~cm}^{-3}$ is the density of water.

To account for effects of time-varying above-ground vegetation on the low-energy neutron counts (Franz et al., 2013; Coopersmith et al., 2014), Franz et al. (2015) proposed the following additional correction factor to $N_{0}$ :

$N_{0}(\mathrm{BWE})=m \cdot \mathrm{BWE}+N_{0}(0)$,

where $N_{0}(0)$ is the instrument-specific estimate of $N_{0}$ with no standing biomass, BWE is the biomass water equivalent $\left(\mathrm{kg} \mathrm{m}^{-2} \sim \mathrm{mm}\right.$ of water $\mathrm{m}^{-2}$ ), and $m$ is the slope of the relationship between $N_{0}$ and BWE, determined via in situ calibration datasets. The BWE is further defined as

$\mathrm{BWE}=\mathrm{SWB}-\mathrm{SDB}+\mathrm{SDB} \cdot f_{\mathrm{WE}}$,

where SWB is the standing wet biomass per unit area $\left(\mathrm{kg} \mathrm{m}^{2} \sim \mathrm{mm}\right.$ of water $\left.\mathrm{m}^{-2}\right)$, SDB is the standing dry biomass per unit area $\left(\mathrm{kg} \mathrm{m}^{2} \sim \mathrm{mm}\right.$ of water $\left.\mathrm{m}^{-2}\right)$, and $f_{\mathrm{WE}}=0.494$ is the stoichiometric ratio of $\mathrm{H}_{2} \mathrm{O}$ to organic carbon (assuming organic carbon is cellulose, $\mathrm{C}_{6} \mathrm{H}_{10} \mathrm{O}_{5}$ ). Using nine in situ calibration datasets for maize and soybean crops, Franz et al. (2015) found their roving CRNP had a statistically significant linear relationship between $N_{0}$ and BWE yielding $N_{0}(0)=518.34$ counts per minute and $m=-4.9506$ $\left(R^{2}=0.515\right.$ and $p$ value $\left.=0.03\right)$. We note the coefficients are less suitable for forest canopies given the need for a neutron geometric efficiency factor described further in the supplemental material of Franz et al. (2013). We also refer the reader to Coopersmith et al. (2014) and Baatz et al. (2015) for further discussion of CRNP use in forest canopies and Bogena et al. (2013) for a discussion of below-ground biomass and litter layers. In addition, plant-specific root-shoot ratios (Peichl et al., 2012) or allometric relationships (Jenkins et al., 2003) may be used to derive a better understanding of the impact of time-varying below-ground biomass on $N_{0}$. This is an open and challenging research area and beyond the scope of the current work.

\subsection{In situ soil and vegetation calibration parameters}

In the simplest form, the calibration function summarized in Eqs. (1)-(4) requires depth-averaged estimates of three soil parameters, $\theta_{\mathrm{LW}}, \theta_{\mathrm{SOC}}$, and $\rho_{\mathrm{b}}$, and two vegetation parameters SWB and SDB. We note that depth-weighted average parameters, belowground biomass, and depth-weighted
SWC are needed to fully understand the decreasing sensitivity of the CRNP with depth as recommended elsewhere (Bogena et al., 2013; Köhli et al., 2015). As a first step, here we will only consider depth- and area-averaged properties given the resolution of the global remote sensing products. We expect future work to improve on these analyses as regional datasets contain higher-spatial-resolution data. In order to estimate depth- and area-averaged soil parameters, Zreda et al. (2012) and Franz et al. (2012) recommended averaging 108 individual in situ soil samples from 18 locations (every $60^{\circ}$ and radii of $25,75,200 \mathrm{~m}$ ) and six depths (every $5 \mathrm{~cm}$ from 0 to $30 \mathrm{~cm}$ ) within a CRNP footprint. In light of recent modeling work (Köhli et al., 2015), this sampling pattern may need to be adjusted to be more representative of encountered conditions (such as shorter sampling distances due to reduced footprint area). Given the mixture of previously published datasets and new datasets used here, we decided to use the original sampling location description. Zreda et al. (2012) found that a composite sample of $1 \mathrm{~g}$ of material gathered from each of the 108 samples was adequate to estimate $\theta_{\mathrm{LW}}$ and $\theta_{\mathrm{SOC}}$. These composite samples can be analyzed directly for lattice water $\left(\mathrm{g} \mathrm{g}^{-1}\right)$, soil total carbon (TC, $\mathrm{g} \mathrm{g}^{-1}$ ), and inorganic carbon (TIC, $\mathrm{g} \mathrm{g}^{-1}$ ) determined by measuring $\mathrm{CO}_{2}$ after the sample is acidified (e.g., by Actlabs of Ontario Canada, analysis codes: 4E-exploration, 4F$\mathrm{CO} 2$, 4F-C, and 4F-H2O+/-). Franz et al. (2015) reported $\theta_{\mathrm{SOC}}=(\mathrm{TC}-\mathrm{TIC}) \cdot 1.724 \cdot f_{\mathrm{WE}}$, where 1.724 is a constant to convert total organic carbon into total organic matter and $f_{\mathrm{WE}}$ is given above. To estimate $\rho_{\mathrm{b}}$ at each location, Zreda et al. (2012) used a $30 \mathrm{~cm}$ long split tube auger, which contained six $5 \mathrm{~cm}$ diameter by $5 \mathrm{~cm}$ length rings. All samples were then averaged to get a composite value.

In order to estimate standing wet biomass (SWB) and standing dry biomass (SDB) in maize and soybeans, Franz et al. (2015) measured average plant density in $1 \mathrm{~m}^{2}$ quadrats at each of the 18 sampling locations. In a subset of six sites (randomly chosen from one radius for each of the six transects) three plants were removed and placed in a paper bag for weighing within $2 \mathrm{~h}$ (to minimize water loss). The plants were then dried for 5 days at $70^{\circ} \mathrm{C}$ and weighed again. Using the density of plants, wet weight, and dry weight, SWB and SDB can be determined at each site and averaged across the CRNP footprint.

\subsection{Global datasets of soil properties}

Shangguan et al. (2014) compiled a $30 \operatorname{arcsec}(\sim 1 \mathrm{~km})$ Global Soil Dataset (GSDE) with 34 soil parameters in 8 layers $(0-0.045,0.045-0.091,0.091-0.166,0.166-$ $0.289,0.289-0.493,0.493-0.829,0.829-1.383$, and $1.383-$ $2.296 \mathrm{~m}$ ). In order to construct an average value relevant to the CRNP, we arithmetically averaged the top four layers in each grid location to form a composite value $(\sim 30 \mathrm{~cm})$ over the CONUS. The GSDE contains estimates of soil bulk density and soil organic carbon. In order to construct a map of 

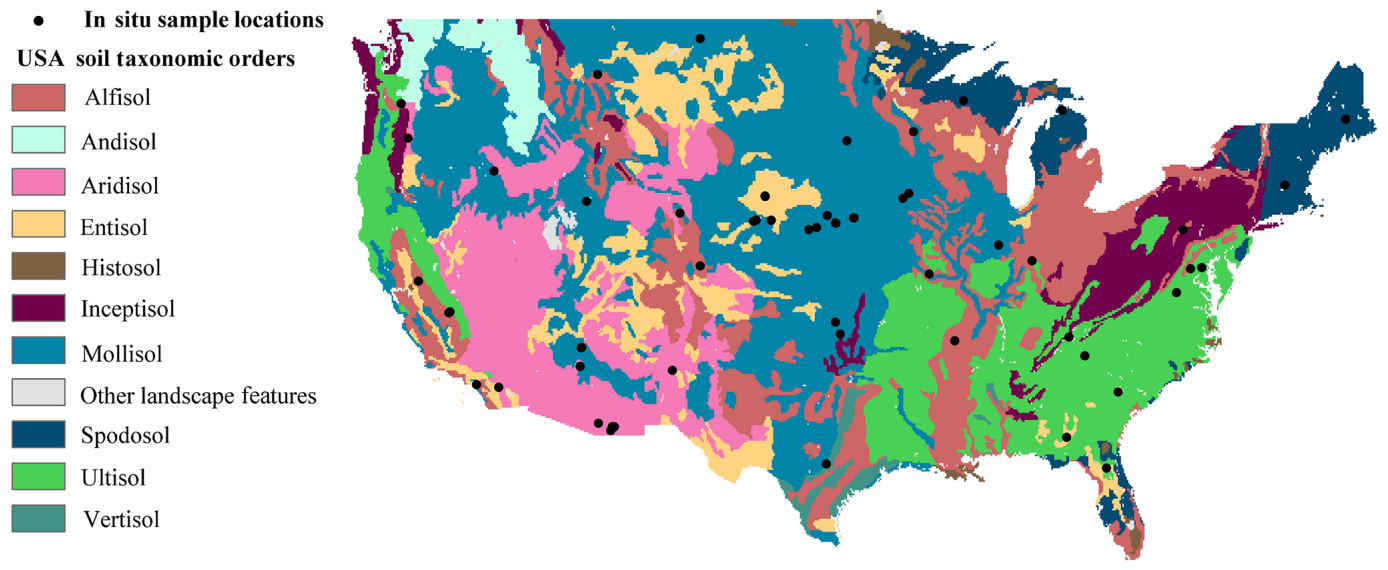

Figure 1. Map of soil taxonomic classification over the continental USA using the 12 US soil taxonomic orders (data source: United Nations, 2007), and M. Kuzila, personal communication, 2014). Note Gelisols are not present in the CONUS. Black dots indicate 61 locations where we have in situ composite/average samples for soil bulk density, soil lattice water, soil organic carbon, and clay weight fraction collected over a 12.6 ha circle and averaged over the top $30 \mathrm{~cm}$ (Table S1 in the Supplement).

lattice water, we explored whether any relationships existed between clay weight fraction and lattice water following the work of Greacen (1981) using active neutron probe calibration procedures developed for Australian soils. In order to account for variations in chemical and physical weathering on lattice water (Zreda et al., 2012), we further partitioned the analyses based on soil order. A global soil order map with a resolution of $5 \operatorname{arcmin}(\sim 8 \mathrm{~km})$ containing $25 \mathrm{ma}-$ jor soil classifications was first uploaded to ArcMap (ESRI, v. 10.2.2) and clipped to the CONUS. The 25 soil classifications were then categorized into 12 major classifications of US soil taxonomy (see Fig. 1, M. Kuzila, University of Nebraska-Lincoln, personal communication, 2014, Soil Survey Staff, 1999). The reduction from 25 to 12 soil classifications allowed us to generate larger sample sizes for each classification from the available calibration datasets. Using the available lattice water samples from Zreda et al. (2012) and additional samples collected in situ over 2014, we analyzed whether any statistically significant relationships existed between GSDE clay weight percent and 61 in situ lattice water samples for each of the US soil orders (Table S1). We note that this procedure could be used globally if in situ lattice water samples were available for all 25 soil taxonomic groups. From these relationships, a map of the CONUS lattice water weight percent was developed by using either the mean value of the in situ lattice water or the linear relationships between clay weight percent (from the GSDE) and the lattice water in situ samples. A statistically significant $p$ value $(<0.05)$ was used to discriminate between using the mean values and linear relationship. Additionally, in situ samples of soil organic carbon, bulk density, and clay weight percent were compared against the same parameters derived from the GSDE.

\subsection{Global datasets of vegetation properties}

In order to estimate SWB and SDB, we downloaded remotely sensed $500 \mathrm{~m}$ MODIS reflectance data from NASA's Terra satellite (http://earthexplorer.usgs.gov/). To calibrate and validate the in situ vegetation data to the remotely sensed vegetation estimates, we sampled two different agricultural areas in eastern Nebraska. The MODIS reflectance data were used to generate a widely used vegetation index (see detailed information below), and then calibrated against historical biomass data (2003-2013) from three fields near Mead, NE. Each field is part of the AmeriFlux network (http://ameriflux. ornl.gov/) with data going back to 2001 (site description given in Suyker et al., 2005). Each field is approximately 65 ha in area. Field 1 (Mead Irrigated/US-Ne1, 41.1650, $\left.-96.4766^{\circ}\right)$ is irrigated with continuous maize. Field 2 (Mead Irrigated Rotation/US-Ne2, 41.1649, $-96.4701^{\circ}$ ) is irrigated with a rotation of maize and soybean. Field $3(\mathrm{Mead}$ Rainfed/US-Ne3, $41.1797,-96.4396^{\circ}$ ) is rainfed with a rotation of maize and soybean. At these three fields, destructive biomass samples were collected approximately every 2 weeks at six different locations in the field, typically consisting of 30-35 individual plants per sampling bout. From the destructive sampling bouts, we were able to compute SWB and SDB. The sites, with their long sampling records consisting of both rainfed and irrigated soybean and maize, are an ideal location for calibrating the remote sensing reflectance data and vegetation indices. In order to validate the derived vegetation index and coefficients from the abovementioned three sites, we used four bouts of destructive biomass sampling at two fields (each $\sim 65$ ha) during 2014 near Waco, NE (Franz et al., 2015). The fields were irrigated maize (40.9482, $\left.-97.4875^{\circ}\right)$ and irrigated soybean $\left(40.9338,-97.4587^{\circ}\right.$ ). SWB and SDB were collected following the protocol described in Sect. 2.3. 
A total of 924 MODIS images over the growing seasons (May to October) between 2003 and 2014 were downloaded for calibration and validation of the corresponding destructive biomass samples at the five field sites in central and eastern Nebraska (note that MODIS images from the closest date to in situ sampling were used with up to a 4-day offset). We extracted the MODIS reflectance data in the green and nearinfrared electromagnetic spectrum range. Next, we removed any pixels that were skewed by incidental cloud cover (NguyRobertson and Gitelson, 2015). The resulting data were then transformed from separate reflectance images into the GrWDRVI (Gietelson, 2004):

GrWDRVI $=\frac{(0.1 \cdot \text { near infrared }- \text { green })}{(0.1 \cdot \text { near infrared }+ \text { green })}$,

where near-infrared light (MODIS band 2) has a wavelength between 841 and $876 \mathrm{~nm}$, and green light (MODIS band 4) has a wavelength between 545 and $565 \mathrm{~nm}$. The GrWDRVI has been shown to have better correlations with observed in situ biomass as compared to other vegetation indices such as normalized difference vegetation index (NDVI; NguyRobertson et al., 2012; Nguy-Robertson and Gitelson, 2015). We then investigated whether any relationships existed between GrWDRVI and SWB as well as between GrWDRVI and SDB. We note that a variety of vegetation indices exist in the literature (cf. Kumar et al., 2015; Duncan et al., 2015) and that this analysis is a first step for use with maize and soybean. We anticipate that other vegetation indices may be more appropriate with use in other crops or vegetation types and more research is needed in this area.

\subsection{Error propagation analysis of GSDE soil properties}

We used a Monte Carlo analysis to estimate the expected uncertainty if the GSDE parameters were used instead of in situ estimates. The statistical metrics of root mean square error (RMSE), mean absolute error (MAE), and bias describe the error propagation in the Monte Carlo simulation experiment. From the 61 CONUS in situ samples and the GSDE soil properties, we estimated the mean difference and the covariance matrix for $\theta_{\mathrm{LW}}, \theta_{\mathrm{SOC}}$, and $\rho_{\mathrm{b}}$. With these data, we simulated 100000 realizations of the "true" (i.e., from the in situ sampling) and perturbed soil properties using a multivariate normal distribution. Using a range of observed neutron counts and solving Eqs. (1)-(2) with the true and perturbed soil properties, we also estimated the true and perturbed SWC. In order to provide realistic constraints on the error propagation results, we assumed soil bulk density was constrained between 1.2 and $1.5 \mathrm{~g} \mathrm{~cm}^{-3}$, lattice water between 1 and $8 \mathrm{wt} \%$, soil organic carbon between 0 and $8 \mathrm{wt} \%$, and SWC between 0.03 and $0.45 \mathrm{~cm}^{3} \mathrm{~cm}^{-3}$. Simulated and calculated values outside of these bounds were either reset to the minimum or maximum value or removed from the Monte Carlo statistics. A minimum threshold of $70 \%$ of simulated cases was used to compute all error statis- tics for each case. We note that the effects of growing biomass were not included here given the lack of available calibration datasets at all sites but could be incorporated in future work following a similar methodology.

\section{Results}

\subsection{Comparison of in situ and global soil calibration parameters}

The comparisons between observed clay weight percent, soil bulk density, soil organic carbon and the GSDE values are summarized in Table S1 and Fig. 2a-c for the 61 sampling sites within the CONUS. Other than one outlier (see discussion in Sect. 4.1), the comparison between the mean observed and GSDE clay weight percent (of sites that had clay weight percent) behaved well (RMSE $\left.=5.45 \mathrm{wt} \%, R^{2}=0.68\right)$ considering the difference in scale and methods. The comparisons between soil bulk density (RMSE $=0.173 \mathrm{~g} \mathrm{~cm}^{-3}$, $R^{2}=0.203$ ) and soil organic carbon as it was during the various 2011-2014 sampling campaigns (RMSE $=1.47 \mathrm{wt} \%$, $R^{2}=0.175$ ) generally followed the same positive trend. We note that the slope of the relationships for soil bulk density and soil organic carbon is different from 1 and can lead to biased results. Caution should be used for using these estimates as opposed to local in situ sampling.

In order to construct a map of the CONUS lattice water, we investigated whether any significant relationships existed between GSDE clay wt $\%$ and observed lattice water for each US soil taxonomic group (Table 1). We found that a significant linear relationship existed between clay wt $\%$ and lattice water for all 61 sites $\left(R^{2}=0.183, p\right.$ value $\left.<0.001\right)$. However, after partitioning the sites into soil taxonomic groups, only the Mollisol taxonomic group yielded a statistically significant relationship $\left(R^{2}=0.539, p\right.$ value $\left.<0.001\right)$. Therefore, in order to construct a CONUS lattice water map, we used the mean values for six taxonomic groups and neglected the remaining five taxonomic groups due to an inadequate number of samples (Fig. 3). Figure 2d illustrates the comparison between the derived and observed lattice water for the 61 CONUS sites (RMSE $=1.299 \mathrm{wt} \%, R^{2}=0.315$ ). Table $\mathrm{S} 1$ summarizes the observed and GSDE values for all 61 sites and Table 2 summarizes the mean difference and covariance matrix between the in situ values and GSDE values. The mean difference and covariance differences were used in the error propagation analysis described in Sects. 2.6 and 3.3. We note that each of the mean differences followed a normal distribution (see Table S1 for in situ and GSDE values).

\subsection{Comparison of in situ and remotely sensed vegetation calibration parameters}

Using the 11 years of destructive vegetation sampling from 3 fields near Mead, NE, we found that the GrWDRVI was able to reasonably predict SWB when partitioning the 
(a)

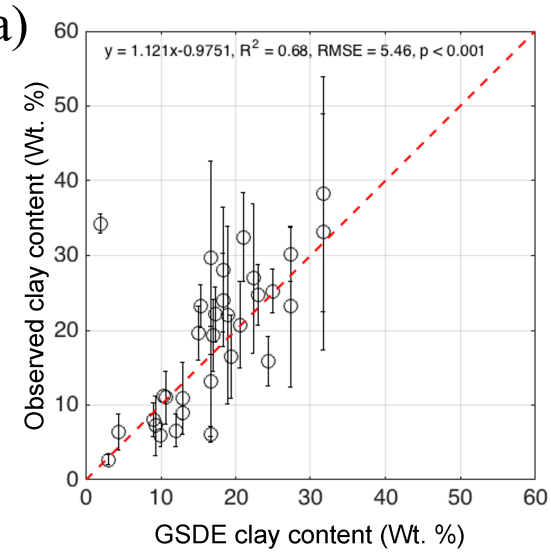

(c)

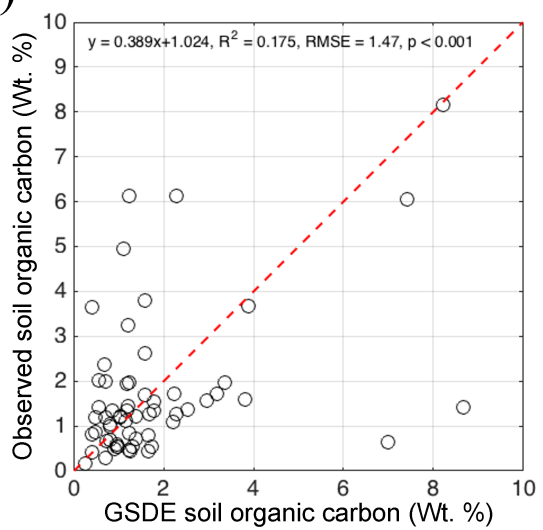

(b)

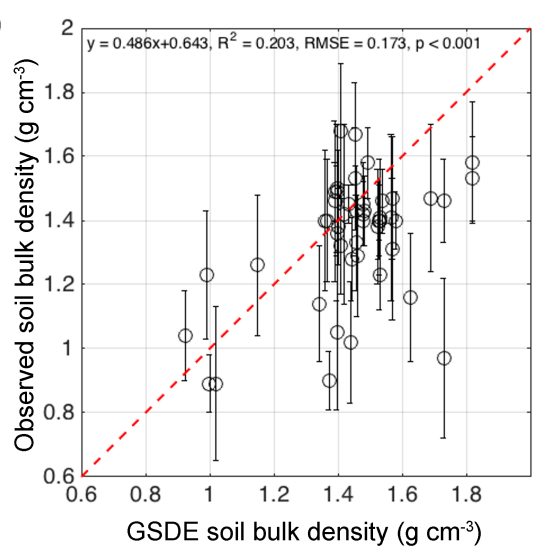

(d)

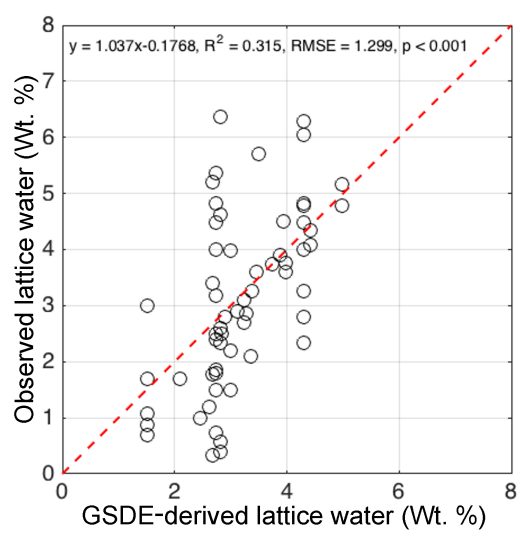

Figure 2. Comparison between 61 in situ composite samples and GSDE values from the closest pixel for (a) clay weight percent, (b) soil bulk density, and (c) soil organic carbon. (d) Comparison between in situ lattice water and derived values using GSDE clay weight fraction and soil taxonomic orders. See Table 1 for summary of data by taxonomic group, Table S1 for raw data, and Table 2 for statistical summary of differences between in situ and GSDE products. Note error bars denote \pm 1 SD (standard deviation).

data into maize and soybean, irrigated and rainfed, and green-up/mature and senescence periods of crop development (Fig. 4 and Tables S2 and S3). Figure $4 a$ and b illustrate the logistic functions that were used to predict SWB for maize green-up (RMSE $=0.88 \mathrm{~kg} \mathrm{~m}^{2}$ ) and soybean green-up $\left(\mathrm{RMSE}=0.47 \mathrm{~kg} \mathrm{~m}^{-2}\right)$. We note that SWB relationships with GrWDRVI indicate that GrWDRVI values less than 0.25 equated to the absence of SWB. During senescence, we found that a second-order power law function fit the data well. We found the maize senescence functions $(\mathrm{DOY}>210)$ needed to be further partitioned by irrigated and rainfed conditions as limitations in soil water will occur more quickly with mature plants that utilize the entire root zone. The resulting functions for irrigated maize during senescence $\left(\mathrm{RMSE}=0.75 \mathrm{~kg} \mathrm{~m}^{-2}\right)$ and rainfed maize during senescence $\left(\mathrm{RMSE}=0.92 \mathrm{~kg} \mathrm{~m}^{-2}\right)$ behaved well. For the soybean senescence function (DOY $>230$ ), we found a single function behaved reasonably well for both irrigated and rainfed conditions (RMSE $=0.45 \mathrm{~kg} \mathrm{~m}^{-2}$ ). As expected from previous research (Ciganda et al., 2008; Peng et al.,
2011), we found that the GrWDRVI was a poor predictor of $\mathrm{SDB} /$ percent water content of the vegetation. We will discuss the reasons and alternative strategies for estimating SDB in Sect. 4.2.

Using the derived relationships from the three study sites near Mead, NE, we applied the equations to our two study sites near Waco, NE $(\sim 88 \mathrm{~km}$ from Mead, NE, Fig. 5 and Tables 3 and 4). Figure 5 illustrates the time series of SWB using the 8-day MODIS product in combination with the derived equations for both field sites. The figure also illustrates the observed destructive sampling for four different sampling bouts. With the limited data, we found the time series of SWB calculated from the MODIS data followed the expected green-up and senescence SWB behavior for both the irrigated maize and soybean. The GrWDRVI-derived SWB largely captured the maximum observed value for both the irrigated maize $\left(6.58 \mathrm{~kg} \mathrm{~m}^{-2}\right.$ vs. $\left.6.2 \mathrm{~kg} \mathrm{~m}^{-2}\right)$ and irrigated soybean $\left(2.61 \mathrm{~kg} \mathrm{~m}^{-2}\right.$ vs. $\left.1.81 \mathrm{~kg} \mathrm{~m}^{-2}\right)$. The largest discrepancy was during the maize green-up period (DOY 183) where the observed value was 2.4 and $\sim 4.0 \mathrm{~kg} \mathrm{~m}^{-2}$ calculated from 
Table 1. Summary of mean and standard deviation of in situ lattice water samples organized by US soil taxonomic groups. The table also summarizes a linear regression analysis using the GSDE clay percent and in situ samples. The last column indicates how the $1 \mathrm{~km}$ CONUS lattice water map was generated. * Note that $\mathrm{n} / \mathrm{a}$ stands for not applicable because of a lack of data.

\begin{tabular}{|c|c|c|c|c|c|c|c|c|}
\hline $\begin{array}{l}\text { USA soil } \\
\text { taxonomic } \\
\text { group }\end{array}$ & $\begin{array}{l}\text { Mean } \\
\text { lattice } \\
\text { water } \\
\text { (wt \%) }\end{array}$ & $\begin{array}{l}\text { SD } \\
\text { lattice } \\
\text { water } \\
\text { (wt \%) }\end{array}$ & $\begin{array}{l}\text { Number } \\
\text { of } \\
\text { samples }\end{array}$ & $\begin{array}{l}\text { Linear } \\
\text { regression } \\
\text { slope }\end{array}$ & $\begin{array}{l}\text { Linear } \\
\text { regression } \\
\text { intercept }\end{array}$ & $\begin{array}{l}\text { Linear } \\
\text { regression } \\
R^{2}\end{array}$ & $\begin{array}{l}\text { Linear } \\
\text { regression } \\
p \text { value }\end{array}$ & $\begin{array}{l}\text { GSDE- } \\
\text { derived } \\
\text { CONUS } \\
\text { lattice } \\
\text { water } \\
\text { product }\end{array}$ \\
\hline Alfisol & 4.31 & 1.36 & 9 & 6.09 & -0.11 & 0.086 & 0.44330 & Mean \\
\hline Andisol & $\mathrm{n} / \mathrm{a}^{*}$ & $\mathrm{n} / \mathrm{a}^{*}$ & $\mathrm{n} / \mathrm{a}^{*}$ & $\mathrm{n} / \mathrm{a}^{*}$ & $\mathrm{n} / \mathrm{a}^{*}$ & $\mathrm{n} / \mathrm{a}^{*}$ & $\mathrm{n} / \mathrm{a}^{*}$ & $\mathrm{n} / \mathrm{a}^{*}$ \\
\hline Aridisol & 2.73 & 1.36 & 10 & 4.82 & -0.15 & 0.095 & 0.38607 & Mean \\
\hline Entisol & 1.47 & 0.93 & 5 & 2.48 & -0.14 & 0.233 & 0.41064 & Mean \\
\hline Gelisol & $\mathrm{n} / \mathrm{a}^{*}$ & $\mathrm{n} / \mathrm{a}^{*}$ & $\mathrm{n} / \mathrm{a}^{*}$ & $\mathrm{n} / \mathrm{a}^{*}$ & $\mathrm{n} / \mathrm{a}^{*}$ & $\mathrm{n} / \mathrm{a}^{*}$ & $\mathrm{n} / \mathrm{a}^{*}$ & $\mathrm{n} / \mathrm{a}^{*}$ \\
\hline Histosol & $\mathrm{n} / \mathrm{a}^{*}$ & $\mathrm{n} / \mathrm{a}^{*}$ & $\mathrm{n} / \mathrm{a}^{*}$ & $\mathrm{n} / \mathrm{a}^{*}$ & $\mathrm{n} / \mathrm{a}^{*}$ & $\mathrm{n} / \mathrm{a}^{*}$ & $\mathrm{n} / \mathrm{a}^{*}$ & $\mathrm{n} / \mathrm{a}^{*}$ \\
\hline Inceptisol & 4.98 & 0.28 & 2 & $\mathrm{n} / \mathrm{a}^{*}$ & $\mathrm{n} / \mathrm{a}^{*}$ & $\mathrm{n} / \mathrm{a}^{*}$ & $\mathrm{n} / \mathrm{a}^{*}$ & Mean \\
\hline Mollisol & 3.18 & 1.22 & 24 & 1.03 & 0.11 & 0.539 & 0.00004 & Linear \\
\hline Oxisol & $\mathrm{n} / \mathrm{a}^{*}$ & $\mathrm{n} / \mathrm{a}^{*}$ & $\mathrm{n} / \mathrm{a}^{*}$ & $\mathrm{n} / \mathrm{a}^{*}$ & $\mathrm{n} / \mathrm{a}^{*}$ & $\mathrm{n} / \mathrm{a}^{*}$ & $\mathrm{n} / \mathrm{a}^{*}$ & $\mathrm{n} / \mathrm{a}^{*}$ \\
\hline Spodosol & 2.68 & 2.10 & 4 & 3.45 & -0.11 & 0.020 & 0.85919 & Mean \\
\hline Ultisol & 2.82 & 2.33 & 6 & 0.28 & 0.20 & 0.229 & 0.33672 & Mean \\
\hline Vertisol & 5.18 & $\mathrm{n} / \mathrm{a}^{*}$ & 1 & $\mathrm{n} / \mathrm{a}^{*}$ & $\mathrm{n} / \mathrm{a}^{*}$ & $\mathrm{n} / \mathrm{a}^{*}$ & $\mathrm{n} / \mathrm{a}^{*}$ & $\mathrm{n} / \mathrm{a}^{*}$ \\
\hline All & 3.16 & 1.58 & 61 & 1.68 & 0.09 & 0.183 & 0.00066 & $\mathrm{n} / \mathrm{a}^{*}$ \\
\hline
\end{tabular}

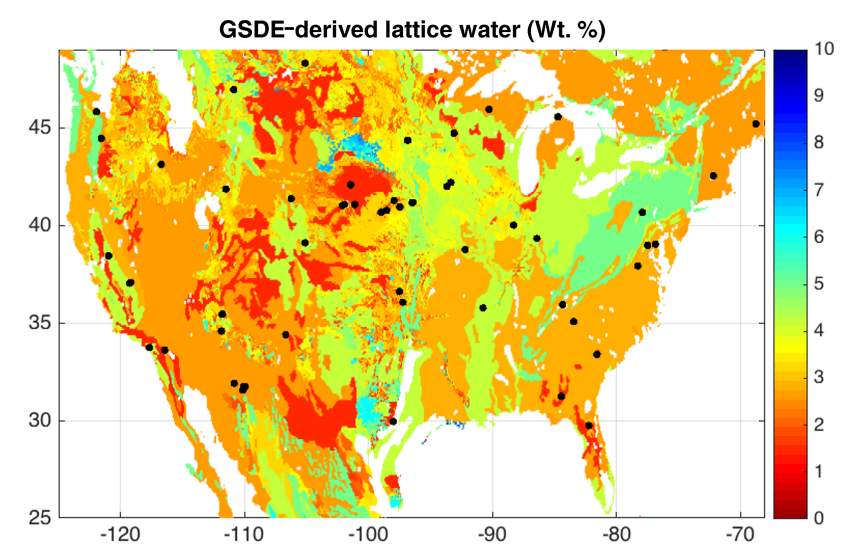

Figure 3. Derived $1 \mathrm{~km}$ resolution lattice water weight percent map using the GSDE clay percent and regression analyses organized by soil taxonomic classification. See Table 1 for estimates of the mean, standard deviation, and linear regression vs. clay percent organized by taxonomic group. Black dots indicate 61 locations where we have in situ composite/average samples for soil bulk density, soil lattice water, soil organic carbon, and clay weight fraction collected over a 12.6 ha circle and averaged over the top $30 \mathrm{~cm}$ (Table S1). Missing areas indicate surface water bodies or soil taxonomic groups with no or limited in situ lattice water sampling (see Table 1).

the GrWDRVI. While the derived equations behaved well for this limited validation dataset, the equations should be tested at additional sites where other crop and soil types may influence the function coefficients. Overall, the equations and
Table 2. Top: summary of mean difference between in situ samples and GSDE values (Fig. 3) for bulk density, lattice water, and organic carbon. Bottom: summary of covariance matrix of difference between in situ values and GSDE values. The mean difference and covariance data were used in an error propagation analysis illustrated in Fig. 6.

\begin{tabular}{lcrr}
\hline & $\begin{array}{c}\text { Bulk } \\
\text { density } \\
\left(\mathrm{g} \mathrm{cm}^{-3}\right)\end{array}$ & $\begin{array}{r}\text { Lattice } \\
\text { water } \\
(\mathrm{wt} \%)\end{array}$ & $\begin{array}{r}\text { Organic } \\
\text { carbon } \\
(\mathrm{wt} \%)\end{array}$ \\
\hline $\begin{array}{l}\text { Mean difference of in situ } \\
\text { value - GSDE value }\end{array}$ & -0.10035 & -0.05789 & -0.07077 \\
\hline \multicolumn{1}{c}{ Covariance matrix of in situ value - GSDE value } \\
\hline $\begin{array}{l}\text { Bulk density }\left(\mathrm{g} \mathrm{cm}^{3}\right) \\
\text { Lattice water (wt \%) }\end{array}$ & 0.0386 & -0.0567 & -0.2077 \\
Organic carbon (wt \%) & & 1.6745 & 0.3624 \\
\hline
\end{tabular}

regression fits resulting in $\mathrm{RMSE}<1 \mathrm{~kg} \mathrm{~m}^{-2}$ are within the uncertainty of destructive biomass sampling in crops (Franz et al., 2013, 2015). We note that $1 \mathrm{~kg} \mathrm{~m}^{-2}$ is approximately equal to $1 \mathrm{~mm}$ of water or about $0.0033 \mathrm{~cm}^{3} \mathrm{~cm}^{-3}$ of SWC over $300 \mathrm{~mm}$. This indicates that for relatively small changes in BWE it will be nearly indistinguishable from the noise in the CRNP measurements. By having general SWB relationships (for eastern Nebraska) through time using the 8-day MODIS data, this could allow for reasonable biomass corrections to $N_{0}$ with minimal effects $\left(<0.01 \mathrm{~cm}^{3} \mathrm{~cm}^{-3}\right)$ on the overall estimation of SWC. 
(a)

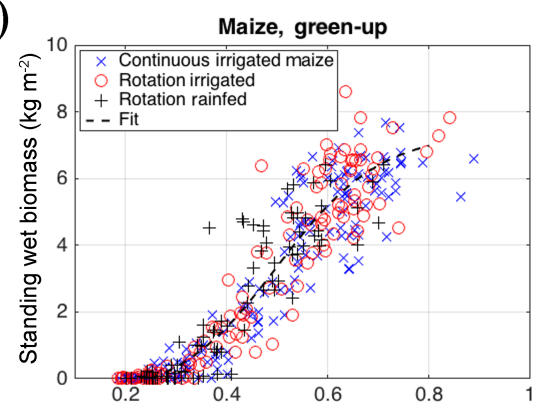

(c)

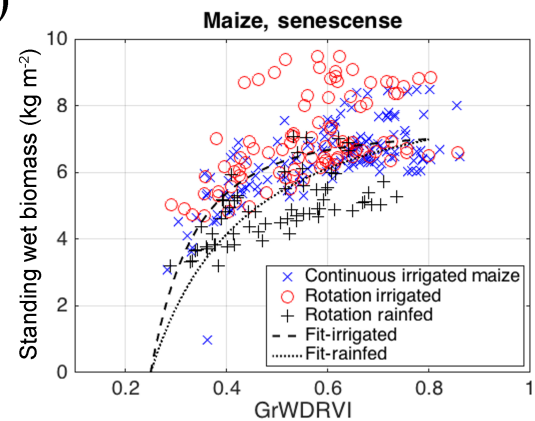

(b)

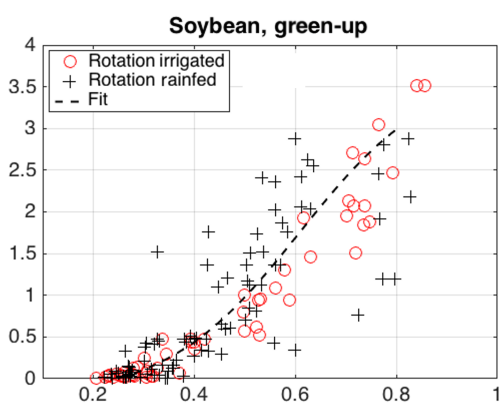

(d)

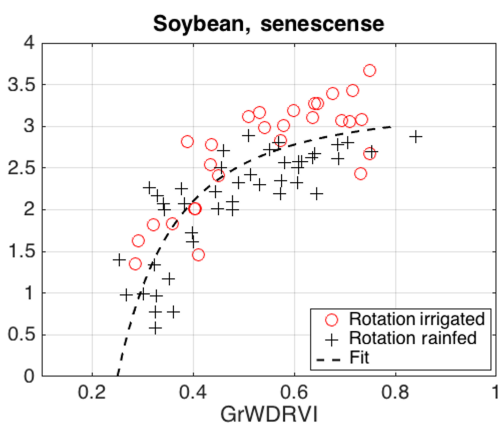

Figure 4. Relationship between GrWDRVI and observed standing weight biomass for maize (a, c) and soybean (b, d) partitioned into greenup (DOY < 210 for maize, DOY < 230 for soybean) and senescence. Destructive vegetation data are aggregated from three fields near Mead, NE, between 2003 and 2013 (Table S2). The regression coefficients and equations are summarized in Table S3. Note that the maize and soybean functions were subject to the constraints in order to provide realistic behavior at the observed GrWDRVI and destructive vegetation sampling bounds. See main text for details.

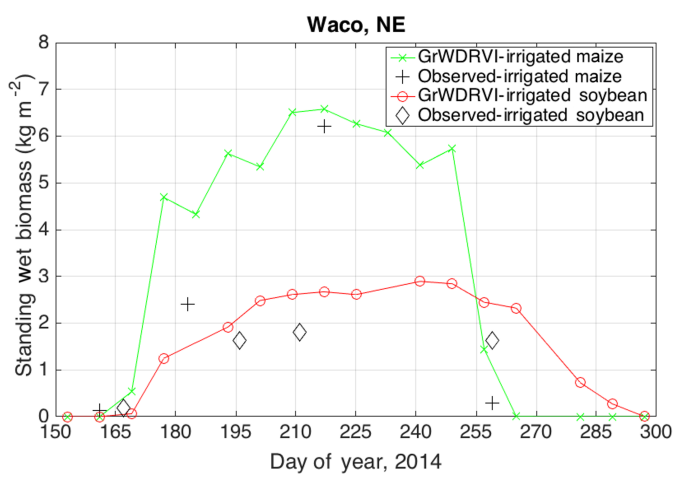

Figure 5. Time series of standing wet biomass for two study sites (irrigated maize and irrigated soybean) near Waco, NE, over the 2014 growing season. The graph contains the observed in situ sampling in addition to the GrWDRVI estimates using the equations summarized in Table S3. See Table 3 for GrWDRVI values and Table 4 for in situ estimates.

\subsection{Results of GSDE soil properties error propagation analysis}

In order to further assess the accuracy of our datasets, we synthetically altered the parameters via a Monte Carlo error analysis. This was done using the GSDE soil parame- ters $\left(\theta_{\mathrm{LW}}, \theta_{\mathrm{SOC}}\right.$, and $\left.\rho_{\mathrm{b}}\right)$ as compared to using local sampling (Fig. 6). The analysis revealed that for the given bounds of $\theta_{\mathrm{LW}}, \theta_{\mathrm{SOC}}$, and $\rho_{\mathrm{b}}$, the maximum RMSE was around $0.035 \mathrm{~cm}^{3} \mathrm{~cm}^{-3}$ at a $\mathrm{SWC}=0.40 \mathrm{~cm}^{3} \mathrm{~cm}^{-3}$. The asymmetric shape of all the curves is expected given the nonlinear calibration function given in Eq. (4) and the bounded nature of soil moisture. We found that $\rho_{\mathrm{b}}$ was by far the most sensitive parameter, followed by $\theta_{\mathrm{LW}}$ and then $\theta_{\mathrm{SOC}}$. We expect the influence of vegetation changes to be small on the overall accuracy of SWC $\left(<0.01 \mathrm{~cm}^{3} \mathrm{~cm}^{-3}\right)$ given the low RMSE described in Sect. $3.2\left(<1 \mathrm{~kg} \mathrm{~m}^{-2}\right.$, which is $\sim 1 \mathrm{~mm}$ of water or $0.0033 \mathrm{~cm}^{3} \mathrm{~cm}^{-3}$ for a soil depth of $300 \mathrm{~mm}$ ). We also note the critical factor in the error propagation analysis is the assumed range of $\rho_{\mathrm{b}}$, given that it is directly multiplied by the gravimetric water content in the calibration function. Therefore, future sampling efforts or evaluations of available datasets should seek to improve the accuracy of bulk density, meaning better estimates of the mean, standard deviation, quantiles, and impact of land use practices on bulk density. 
Table 3. Summary of 2014 GrWDRVI and calculated standing wet biomass for irrigated maize and irrigated soybean fields near Waco, NE. Note that the senescence equation was applied to DOY 209 for the irrigated maize field as planting date and development can vary locally. The drop in GrWDRVI between DOY 201 and 209 is a clear indicator of change in plant growth stage that can be used on a fieldby-field basis. ${ }^{*}$ Note that $\mathrm{n} / \mathrm{a}$ stands for not applicable because of a lack of data.

\begin{tabular}{lclll}
\hline DOY (2014) & $\begin{array}{c}\text { GrWDRVI-, } \\
\text { irrigated } \\
\text { maize }\end{array}$ & $\begin{array}{l}\text { GrWDRVI- } \\
\text { irrigated } \\
\text { soybean }\end{array}$ & $\begin{array}{l}\text { Calculated } \\
\text { standing } \\
\text { wet biomass- } \\
\text { irrigated } \\
\text { maize } \\
\left(\mathrm{kg} \mathrm{m}^{-2}\right)\end{array}$ & $\begin{array}{l}\text { Calculated } \\
\text { standing } \\
\text { wet biomass- } \\
\text { irrigated } \\
\text { soybean } \\
\left(\mathrm{kg} \mathrm{m}^{-2}\right)\end{array}$ \\
\hline 153 & & & 0.00 & 0.00 \\
161 & & & 0.00 & 0.00 \\
169 & 0.23 & 0.23 & 0.53 & 0.06 \\
177 & 0.24 & 0.24 & 4.69 & 1.25 \\
185 & 0.32 & 0.28 & 4.33 & $\mathrm{n} / \mathrm{a}^{*}$ \\
193 & 0.57 & 0.54 & 5.63 & 1.91 \\
201 & 0.55 & $\mathrm{n} / \mathrm{a}^{*}$ & 5.34 & 2.48 \\
209 & 0.63 & 0.63 & $6.50^{*}$ & 2.61 \\
217 & 0.61 & 0.71 & 6.58 & 2.67 \\
225 & 0.55 & 0.73 & 6.27 & 2.61 \\
233 & 0.57 & 0.74 & 6.07 & $\mathrm{n} / \mathrm{a}^{*}$ \\
241 & 0.50 & 0.73 & 5.38 & 2.89 \\
249 & 0.47 & 0.74 & 5.73 & 6.77 \\
257 & 0.40 & 0.68 & 1.44 & 6.07 \\
265 & 0.43 & 0.64 & 0.00 & 5.83 \\
281 & 0.27 & 0.47 & 0.00 & 2.02 \\
289 & 0.25 & 0.44 & 0.00 & 0.78 \\
297 & 0.21 & 0.28 & 0.00 & 0.00 \\
\hline
\end{tabular}

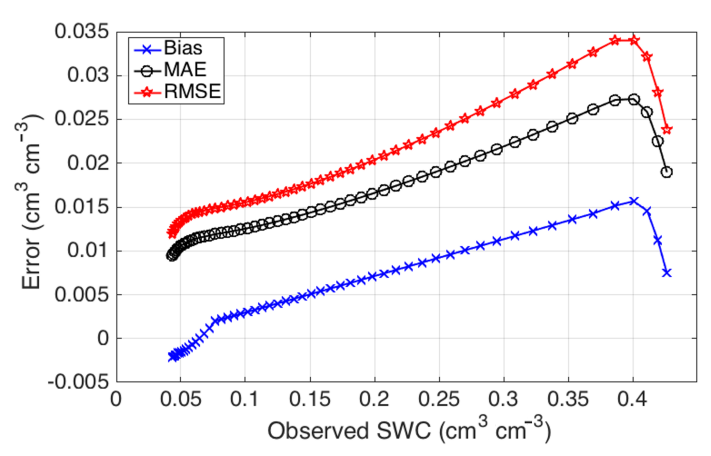

Figure 6. Propagation of error analysis using Monte Carlo simulations of 100000 soil parameter datasets of true soil parameters (i.e., soil bulk density, lattice water, soil organic carbon) and perturbed parameters with matching mean differences and covariance matrix between in situ samples and GSDE-derived parameters (see Table 2). Three error metrics are presented across a range of neutron counts (and thus SWC values). Note that soil bulk density was constrained to $1.2-1.5 \mathrm{~g} \mathrm{~cm}^{-3}$, lattice water from 1 to $8 \mathrm{wt} \%$, soil organic carbon from 0 to $8 \mathrm{wt} \%$, and soil water content from 0.03 to $0.45 \mathrm{~cm}^{3} \mathrm{~cm}^{-3}$. Simulated and calculated values outside of these bounds were either reset to the minimum or maximum or removed from the Monte Carlo statistics. A minimum threshold of $70 \%$ of simulated cases was used to compute error statistics.
Table 4. Summary of 2014 observed standing wet biomass for irrigated maize and irrigated soybean fields near Waco, NE. The observations represent the aggregation of 18 plants collected at 6 different locations across the field on the sampling date.

\begin{tabular}{lccc}
\hline $\begin{array}{l}\text { DOY (2014), } \\
\text { irrigated } \\
\text { soybean }\end{array}$ & $\begin{array}{c}\text { Observed } \\
\text { standing } \\
\text { wet biomass- } \\
\text { irrigated } \\
\text { soybean } \\
\left(\mathrm{kg} \mathrm{m}^{-2}\right)\end{array}$ & $\begin{array}{c}\text { DOY (2014), } \\
\text { irrigated } \\
\text { maize }\end{array}$ & $\begin{array}{c}\text { Observed } \\
\text { standing } \\
\text { wet biomass- } \\
\text { irrigated } \\
\text { maize } \\
\left(\mathrm{kg} \mathrm{m}^{-2}\right)\end{array}$ \\
\hline 167 & 0.19 & 161 & 0.13 \\
196 & 1.63 & 183 & 2.40 \\
211 & 1.81 & 217 & 6.22 \\
259 & 1.63 & 259 & 0.30 \\
\hline
\end{tabular}

\section{Discussion}

\subsection{Global soil calibration parameters}

The correlation between observed and GSDE clay content was very strong (Fig. 2a) for all 61 sites in the CONUS except for the site in south central Texas $\left(29.9492,-97.9966^{\circ}\right)$. The site occurred near a transition from Vertisol to Alfisol soil taxonomic groups; the site may have been improperly categorized (Table S1) or may have straddled a sharp gradient in clay contents. The strong correlation of the GSDE clay content with the observed values allowed us to use the GSDE clay content in understanding the correlation between clay content and lattice water organized by US soil taxonomic groups (Table 1). A strong correlation was only found for clay content and lattice water for the Mollisol soil taxonomic group (see Greacen, 1981; Zreda et al., 2012). This strong correlation is significant because large areas of the Midwest and Great Plains regions of the United States are made up of Mollisol soils. Globally, Mollisol soils comprise about $7 \%$ of the land surface (United Nations, 2007) but contain some of the most highly productive grassland and crop areas (i.e., central USA, Argentina, central Eurasia). As such, the roving CRNP method remains applicable within grassland agricultural settings. No significant linear relationships with clay content were found for Alfisol, Aridisol, Entisol, Inceptisol, Spodosol, or Ultisol. Instead the mean value was assigned to the Alfisol, Aridisol, Entisol, Inceptisol, Spodosol, and Ultisol soil taxonomic groups when generating the CONUS map. We found the differences in most of the soil taxonomic mean values were statistically significant among different taxonomic groups given the small standard errors of the means (not shown but can be calculated from data in Table 1). The current analysis did not contain enough samples for the soil taxonomic groups of Andisol, Gelisol, Histosol, Oxisol, or Vertisol to perform a linear regression or assign a mean value. We recommend future work to consider repeating the analysis for a larger dataset using the FAO 2007 (United Nations, 
2007) soil classification of all 25 groups (also classified for our sites in Table S1). Given the widespread interest in both the fixed and roving cosmic-ray technology, a database of lattice water and clay content for each site could be developed. In addition, warehouses like the Natural Resources Conservation Service (NRCS) in Lincoln, NE, contain stored samples from around the USA. This warehouse, and other soil repositories around the globe, could be sampled in order to complete the global dataset for use by the cosmic-ray community. Finally, the NRCS regularly updates the Soil Survey Geographic Database (SSURGO), which contains higher spatial resolution and vertically resolved estimates of soil texture and structure (i.e., clay content and bulk density). With the defined regression relationships and soil taxonomic groups, better spatial maps of lattice water could be generated. This may become important for applications of the rover at scales less than $1 \mathrm{~km}$, such as using it for applications in precision agriculture as well as increasing the reliability of the calibration function.

The correlation between the observed and GSDE soil organic carbon was fairly poor, particularly at the high end (> $4 \mathrm{wt} \%$ ). The history of land use is critical in determining carbon pools and how they change through time (Post and Kwon, 2000) and may not be well represented in the GSDE. For arable lands, we note that organic carbon has a relatively small impact on the calibration function as it is multiplied by several factors in the calibration equation and is relatively low and homogeneously distributed in the A horizon due to land management activities. However, in grassland and forest sites, high SOC amounts and strong SOC vertical gradients typically exist in the top soil and may need to be quantified with local in situ sampling (e.g., Bogena et al., 2013). For rover survey experiments in these areas, we suggest that SOC be sampled with composite samples, particularly between sites with varying land use histories which can be identified using historical land cover maps.

Observed in situ soil bulk density and GSDE bulk density exhibited a positive relationship, albeit with low $R^{2}$. The poor fit and sensitivity of the parameter in the calibration function increases the importance of identifying the range and variability of bulk density within the rover sample domain. The variability shown here by the standard deviation of the bulk density for the individual point samples within the 28 ha sample domain varied between 0.1 and $0.2 \mathrm{~g} \mathrm{~cm}^{-3}$. Moreover, estimating the quantiles of bulk density at a site is key given the propagation of error analysis presented in Sect. 3.3. Thus, this result supports direct sampling at key locations (along gradients of land use, soil taxonomic groups, etc.) to constrain the quantiles of expected bulk density values. We also suggest that, for rover surveys in the USA (and regional elsewhere), additional higherresolution datasets like SSURGO and its derivatives (e.g., Polaris; Chaney et al., 2016) be used instead of the $1 \mathrm{~km}$ GSDE (in particular bulk density data as a function of depth), as significant small-scale variability may be averaged out.
This may be critical to account for in future roving CRNP research areas, such as precision agriculture or small-scale watershed monitoring where significant soil texture variation may exist at short length scales. We note that this analysis is a first step in the incorporation of existing soil databases that will no doubt continue to increase in spatial resolution and accuracy. Given the increasing use of the roving CRNP technology, we anticipate similar analyses and procedures will be undertaken on regional and local scales from existing and new databases as they become available.

\subsection{Global remotely sensed vegetation calibration parameters}

The comparison of 11 years of destructive vegetation samples from maize and soybeans at 3 sites in eastern Nebraska indicated that the GrWDRVI was able to predict SWB in agricultural fields, especially when partitioned into greenup vs. senescence and irrigated vs. rainfed (Fig. 4). However, as expected the GrWDRVI was unable to predict SDB. The main reason is as the plants begin to dry out during the late summer and early fall, leaves lose their chlorophyll and leaf structure begins to collapse thereby increasing reflected green and reducing near-infrared light (Ciganda et al., 2008; Peng et al., 2011). This is exaggerated by a change in the allocation of resources by the plant from leaves to grain, shifting where the majority of mass is located and thus weakening the capacity for the GrWDRVI to predict SDB. This biological investment of resources is more pronounced for maize than soybeans. As additional crops are included in this analysis, the location and development of the fruit and seed will impact the predictive relationships using vegetation indices. We refer to the reader to Duncan et al. (2015) and Kumar et al. (2015) for a recent review of vegetation indices in remote sensing.

While the developed regression relationships for maize and soybean (Table S3) were tested against independent biomass estimates from Waco, NE (Fig. 5), we note that further validation is needed. In terms of a strategy for estimating SDB, we suggest that proxies such as crop type and growth stage be used. Franz et al. (2013, 2015) found that in early stages, maize and soybean had canopy water contents from 75 to $90 \mathrm{wt} \%$. By the end of senescence before harvest, the canopy water contents were down to $25-35 \mathrm{wt} \%$, and thus very low BWE and minimal impact on the low-energy neutron intensity. If growth stage is not directly known, local meteorological observations, planting date, and crop variety can be used to compute proxies (e.g., growing degree days) or simulated from crop models (Allen et al., 1998). We note that having a reasonably accurate estimate of SWB and thus BWE (within $\sim 1 \mathrm{~kg} \mathrm{~m}^{2}$ ) is all that is required to have a relatively small impact $\left(<0.01 \mathrm{~cm}^{3} \mathrm{~cm}^{-3}\right)$ on the estimated SWC. Finally, we note that this methodology is not applicable to areas with woody biomass. Following Franz et al. (2013), Hawdon et al. (2014), Baatz et al. (2015), and 
Coopersmith et al. (2014) we suggest other vegetation relationships (i.e., BWE vs. $N_{0}$ ) be defined. However, given the relatively small changes in BWE over the year in forests, we would expect small changes in $N_{0}$ through time. For a more complete discussion of CRNP calibration in forests and estimates of time-varying changes in $N_{0}$, please see Bogena et al. (2013) and Heidbüchel et al. (2016).

\subsection{Roving CRNP survey recommendations}

With the continuing use of the roving CRNP we make the following recommendations for best calibration and use:

1. Collect a series of full calibration datasets $\left(\theta_{\mathrm{LW}}, \theta_{\mathrm{SOC}}\right.$, $\left.\rho_{\mathrm{b}}, \mathrm{SWB}, \mathrm{SDB}\right)$ in different land use areas and soil types in order to estimate the instrument-specific slope and intercept for dependence of $N_{0}$ with BWE.

2. In the rover sampling area, construct a map of land use including descriptions of vegetation/crop type, planting date, variety, rainfed vs. irrigated, and gravel vs. paved roads vs. natural areas (see Chrisman and Zreda, 2013, for a discussion of road influence on neutron counts).

3. Collect a series of aggregate soil samples for soil organic carbon and lattice water around the survey area. The samples should be collected across land use, soil texture, and soil taxonomic groups. The GSDE or more local datasets like SSURGO and Polaris (Chaney et al., 2016) in the USA can be used to select sites, cross validate samples, and fill in data gaps.

4. Soil bulk density is the critical parameter in the calibration equations and overall accuracy of the cosmic-ray neutron method. Bulk density should be collected locally wherever possible to determine reasonable quantiles. More local datasets like SSURGO and Polaris in the USA will likely perform better at smaller scales than the $1 \mathrm{~km}$ GSDE.

5. SWC validation datasets should be collected to independently assess the accuracy of the rover survey results.

\section{Summary and conclusions}

In this work, we developed a framework using globally available datasets for estimating four $\left(\theta_{\mathrm{LW}}, \theta_{\mathrm{SOC}}, \rho_{\mathrm{b}}, \mathrm{SWB}\right)$ of the five key soil and vegetation parameters needed by the roving cosmic-ray neutron method for estimating SWC in fast-growing vegetation areas such as row crop production in agricultural areas. The remaining crop vegetation parameter (SDB) can be fairly well approximated by crop type and growth stage or simulated with crop models. The accuracy of the GSDE soil database was tested against 61 calibration datasets from the CONUS. We found that the $1 \mathrm{~km}$ GSDE compares well against observed clay content $\left(R^{2}=0.68\right)$ but much poorer against soil bulk density $\left(R^{2}=0.203\right)$ and soil organic carbon $\left(R^{2}=0.175\right)$. Surprisingly, of the six soil taxonomic groups we investigated, only Mollisols showed a statistically significant correlation with clay content. The remaining five soil taxonomic groups we investigated did show statistically different mean values. These mean values were used to generate a map (not complete) of lattice water for the CONUS. From 11 years of destructive sampling of maize and soybean fields in eastern Nebraska, we found that the 8-day $500 \mathrm{~m}$ resolution MODIS-derived GrWDRVI was highly correlated to SWB, particularly when partitioning the fields into green-up vs. senescence and irrigated vs. rainfed (RMSE $<1 \mathrm{~kg} \mathrm{~m}^{-2}$ ). A propagation of error analysis indicated that the range of bulk density values was the most sensitive calibration parameter. For the selected ranges, we found the GSDE vs. local sampling resulted in a maximum RMSE of $0.035 \mathrm{~cm}^{3} \mathrm{~cm}^{-3}$ at a $\mathrm{SWC}=0.40 \mathrm{~cm}^{3} \mathrm{~cm}^{-3}$. Finally, a list of best practices for future roving CRNP experiments is provided.

\section{Data availability}

The $1 \mathrm{~km}$ global soil database used in this paper is provided by Shangguan et al. (2014) and resources within. The $8 \mathrm{~km}$ global soil taxonomy database is provided by United $\mathrm{Na}-$ tions (2007) and resources within. The US soil taxonomy information is provided by Soil Survey Staff (1999) and resources within. The remaining datasets are provided in the supplemental material associated with this paper. The compiled CONUS $1 \mathrm{~km}$ database can be requested directly from the corresponding author.

\section{The Supplement related to this article is available online at doi:10.5194/hess-20-3859-2016-supplement.}

Acknowledgements. This research is supported financially by the Daugherty Water for Food Global Institute at the University of Nebraska, NSF EPSCoR FIRST Award, the Cold Regions Research Engineering Laboratory through the Great Plains CESU, and a USGS104b grant. We would also like to thank Chase Johnson and Romher Farms for providing access to field sites, Gary Womack and Darin Desilets for support with the rover, and Mark Kuzila for assistance with soil taxonomy. We sincerely appreciate the support and the use of facilities and equipment provided by the Center for Advanced Land Management Information Technologies, School of Natural Resources, and data from Carbon Sequestration Program, the University of Nebraska-Lincoln.

Edited by: H.-J. Hendricks Franssen

Reviewed by: three anonymous referees 


\section{References}

Allen, R. G., Pereira, L. S., Raes, D., and Smith, M.: Crop evapotranspiration. Guidelines for Computing Crop Water Requirements, FAO Irrigation and Drainage Paper 56, Food and Agriculture Organization of the United Nations, Rome, Italy, 1998.

Baatz, R., Bogena, H. R., Franssen, H. J. H., Huisman, J. A., Qu, W., Montzka, C., and Vereecken, H.: Calibration of a catchment scale cosmic-ray probe network: A comparison of three parameterization methods, J. Hydrol., 516, 231-244, doi:10.1016/j.jhydrol.2014.02.026, 2014.

Baatz, R., Bogena, H. R., Hendricks Franssen, H. J., Huisman, J. A., and Montzka, C.: An Empirical Vegetation Correction for Soil Water Content Quantification Using Cosmic Ray Probes, Water Resour. Res., 51, 2030-2046, 2015.

Beven, K. J., and Cloke, H. L.: Comment on "Hyperresolution global land surface modeling: Meeting a grand challenge for monitoring Earth's terrestrial water" by Eric F. Wood et al., Water Resour. Res., 48, W01801, doi:10.1029/2011WR010982, 2012.

Binley, A., Hubbard, S. S., Huisman, J. A., Revil, A., Robinson, D. A., Singha, K., and Slater L. D.: The Emergence of Hydrogeophysics for Improved Understanding of Subsurface Processes Over Multiple Time Scales, Water Resour. Res., 51, 3837-3866, doi:10.1002/2015WR017016, 2015.

Bogena, H. R., Huisman, J. A., Baatz, R., Hendricks Frassen, H. J., and Vereecken, H.: Accuracy of the Cosmic-Ray Soil Water Content Probe in Humid Forest Ecosystems: The Worst Case Scenario, Water Resour. Res., 49, 5778-5791, doi:10.1002/wrcr.20463, 2013.

Bogena, H. R., Huisman, J. A., Guntner, A., Hubner, C., Kusche, J., Jonard, F., Vey, S., and Vereecken, H.: Emerging methods for noninvasive sensing of soil moisture dynamics from field to catchment scale: a review, Wiley Interdisciplinary ReviewsWater, 2, 635-647, doi:10.1002/wat2.1097, 2015.

Chaney, N. W., Wood, E. F., McBratney, A. B., Hempel, J. W., Nauman, T. W., Brungard, C. W., and Odgers, N. P.: POLARIS: A 30-meter probabilistic soil series map of the contiguous United States, Geoderma, 274, 54-67, doi:10.1016/j.geoderma.2016.03.025, 2016.

Chrisman, B. and Zreda, M.: Quantifying mesoscale soil moisture with the cosmic-ray rover, Hydrol. Earth Syst. Sci., 17, 50975108, doi:10.5194/hess-17-5097-2013, 2013.

Ciganda, V., Gitelson, A. A., and Schepers, J.: Vertical Profile and Temporal Variation of Chlorophyll in Maize Canopy: Quantitative "Crop Vigor" Indicator by Means of Reflectance-Based Techniques, Agron. J., 100, 1409-1417, doi:10.2134/agronj2007.0322, 2008.

Coopersmith, E. J., Cosh, M. H., and Daughtry, C. S. T.: FieldScale Moisture Estimates using COSMOS Sensors: A Validation Study with Temporary Networks and Leaf-Area Indices, J. Hydrol., 519, 637-643, doi:10.1016/j.jhydrol.2014.07.060, 2014.

Crow, W. T., Berg, A. A., Cosh, M. H., Loew, A., Mohanty, B. P., Panciera, R., de Rosnay, P., Ryu, D., and Walker, J. P.: Upscaling Sparse Ground-Based Soil Moisture Observations For The Validation Of Coarse-Resolution Satellite Soil Moisture Products, Rev. Geophys., 50, RG2002, doi:10.1029/2011rg000372, 2012.

Desilets, D. and Zreda, M.: Footprint Diameter for a Cosmic-Ray Soil Moisture Probe: Theory and Monte Carlo Simulations, Water Resour. Res., 49, 3566-3575, doi:10.1002/wrcr.20187, 2013.
Desilets, D., Zreda, M., Ferre, T. P. A.: Nature's Neutron Probe: Land Surface Hydrology at an Elusive Scale with Cosmic-Rays, Water Resour. Res., 56, W11505, doi:10.1029/2009wr008726, 2010.

Dong, J. N., Ochsner, T. E., Zreda, M., Cosh, M. H., and Zou, C. B.: Calibration and Validation of the COSMOS Rover for Surface Soil Moisture Measurement, Vadose Zone J., 13, doi:10.2136/vzj2013.08.0148, 2014.

Duncan, J. M. A, Dash, J., and Atkinson, P. M.: The potential of satellite-observed crop phenology to enhance yield gap assessments in smallholder landscapes, Front. Environ. Sci., 3, doi:10.3389/fenvs.2015.00056, 2015.

Entekhabi, D., Njoku, E. G., Neill, P. E., Kellogg, K. H., Crow, W. T., Edelstein, W. N., and Kimball, J.: The Soil Moisture Active Passive (SMAP) Mission, Proc. IEEE, 98, 704-716, 2010.

FAO - United Nations Food and Agriculture Organization: How to Feed the World in 2050, High Level Expert Forum, Rome, Italy, 2009.

Franz, T. E., Zreda, M., Ferre, P. A., Rosolem, R., Zweck, C., Stillman, S., Zeng, X., and Shutt, W. J.: Measurement Depth of The Cosmic-Ray Soil Moisture Probe Affected by Hydrogen From Various Sources, Water Resour. Res., 48, W08515, doi:10.1029/2012WR011871, 2012.

Franz, T. E., Zreda, M., Rosolem, R., Hornbuckle, B. K., Irvin, S. L., Adams, H., Kolb, T. E., Zweck, C., and Shuttleworth, W. J.: Ecosystem-Scale Measurements of Biomass Water using Cosmic-ray Neutrons, Geophys. Res. Lett., 40, 1-5, doi:10.1002/grl.50791, 2013.

Franz, T. E., Wang, T., Avery, W., Finkenbiner, C., and Brocca, L.: Combined Analysis of Soil Moisture Measurements from Roving and Fixed Cosmic-Ray Neutron Probes for Multiscale Real-Time Monitoring, Geophys. Res. Lett., 42, 3389-3396, doi:10.1002/2015GL063963, 2015.

Gietelson, A. A.: Wide Dynamic Range Vegetation Index for Remote Quantification of Biophysical Characteristics of Vegetation, J. Plant Physiol., 161, 165-173, 2004.

Greacen, E. L.: Soil water assessment by the neutron method, CSIRO, Australia, 1981.

Hawdon, A., McJannet, D., and Wallace, J.: Calibration and Correction Procedures for Cosmic-Ray Neutron Soil Moisture Probes Located Across Australia, Water Resour. Res., 50, 5029-5043, doi:10.1002/2013WR015138, 2014.

Heidbüchel, I., Guntner, A., and Blume., T.: Use of cosmic-ray neutron sensors for soil moisture monitoring in forests, Hydrol. Earth Syst. Sci., 20, 1269-1288, doi:10.5194/hess-20-12692016, 2016.

Iwema, J., Rosolem, R., Baatz, R., Wagener, T., and Bogena, H. R.: Investigating temporal field sampling strategies for sitespecific calibration of three soil moisture-neutron intensity parameterisation methods, Hydrol. Earth Syst. Sci., 19, 3203-3216, doi:10.5194/hess-19-3203-2015, 2015.

Jenkins, J. C., Chojnacky, D. C., Heath, L. S., and Birdsey, R. A.: National-scale biomass estimators for United States tree species, Forest Science, 49, 12-35, 2003.

Kerr, Y. H., Waldteufel, P., Wigneron, J. P., Delwart, S., Cabot, F. O., Boutin, J., and Juglea, S. E.: The SMOS Mission: New Tool for Monitoring Key Elements of the Global Water Cycle, Proc. IEEE, 98, 666-687, 2010. 
Köhli, M., Schrön, M., Zreda, M., Schmidt, U., Dietrich, P., and Zacharias, S.: Footprint Characteristics Revised for Field-Scale Soil Moisture Monitoring with Cosmic-Ray Neutrons, Water Resour. Res., 51, 5772-5790, doi:10.1002/2015WR017169, 2015.

Korres, W., Reichenau, T. G., Fiener, P., Koyama, C. N., Bogena, H. R., Comelissen, T., Baatz, R., Herbst, M., Diekkruger, B., Vereecken, H., and Schneider, K.: Spatio-temporal soil moisture patterns - A meta-analysis using plot to catchment scale data, J. Hydrol., 520, 326-341, doi:10.1016/j.jhydrol.2014.11.042, 2015.

Kumar, L., Sinha, P., Taylor, S., and Alqurashi, A. F.: Review of the use of remote sensing for biomass estimation to support renewable energy generation, J. Appl. Remote Sens., 9, 097696, doi:10.1117/1.jrs.9.097696, 2015.

Lv, L., Franz, T. E., Robinson, D. A., and Jones, S. B.: Measured and Modeled Soil Moisture Compared with Cosmic-Ray Neutron Probe Estimates in a Mixed Forest, Vadose Zone J., 13, doi:10.2136/vzj2014.06.0077, 2014.

McJannet D., Franz, T. E., Hawdon, A., Boadle, D., Baker, B., Almeida, A., Silberstein, R., Lambert, T., and Desilets, D.: Field Testing of the Universal Calibration Function for Determination of Soil Moisture With Cosmic-Ray Neutrons, Water Resour. Res., 50, 5235-5248, doi:10.1002/2014WR015513, 2014.

Mekonnen, M. M. and Hoekstra, A. Y.: The green, blue and grey water footprint of crops and derived crop products, Hydrol. Earth Syst. Sci., 15, 1577-1600, doi:10.5194/hess-15-15772011, 2011.

Nguy-Robertson, A. L. and Gitelson, A. A.: Algorithms for estimating green leaf area index in $\mathrm{C} 3$ and $\mathrm{C} 4$ crops for MODIS, Landsat TM/ETM+, MERIS, Sentinel MSI/OLCI, and Venus sensors, Remote Sens. Lett., 6, 1336-1347, doi:10.1080/2150704X.2015.1034888, 2015.

Nguy-Robertson, A. L., Gitelson, A., Peng, Y., Viña, A., Arkebauer, T., and Rundquist, D.: Green Leaf Area Index Estimation in Maize and Soybean: Combining Vegetation Indices to Achieve Maximal Sensitivity, Agron. J., 104, 360-369, doi:10.2134/agronj2012.0065, 2012.

Njoku, E. G. and Entekhabi, D.: Passive Microwave Remote Sensing of Soil Moisture, J. Hydrol., 184, 101-129, 1996.

Peichl, M., Leava, N. A., and Kiely, G.: Above- and belowground ecosystem biomass, carbon and nitrogen allocation in recently afforested grassland and adjacent intensively managed grassland, Plant Soil, 350, 281-296, 2012.

Peng, Y., Gitelson, A. A., Keydan, G., Rundquist, D. C., and Moses, W.: Remote Estimation of Gross Primary Production in Maize and Support for a New Paradigm Based on Total Crop Chlorophyll Content, Remote Sens. Envirion., 115, 978-989, doi:10.1016/j.rse.2010.12.001, 2011.

Post, W. M. and Kwon, K. C.: Soil Carbon Sequestration and LandUse Change: Processes and Potential, Global Change Biol., 6, 317-327, doi:10.1046/j.1365-2486.2000.00308.x, 2000.

Renzullo, L. J., van Dijk, A. I. J. M., Perraud, J. M., Collins, D., Henderson, B., Jin, H., Smith, A. B., and McJannet, D. L.: Continental Satellite Soil Moisture Data Assimilation Improves RootZone Moisture Analysis for Water Resources Assessment, J. Hydrol., 519, 2747-2762, 2014.

Robinson, D. A., Binley, A., Crook, N., Day-Lewis, F. D., Ferre, T. P. A., Grauch, V. J. S., Knight, R., Knoll, M., Lakshmi, V., Miller, R., Nyquist, J., Pellerin, L., Singha, K., and Slater, L.:
Advancing process-based watershed hydrological research using near-surface geophysics: a vision for, and review of, electrical and magnetic geophysical methods, Hydrol. Process., 22, 3604 3635, 2008.

Rosolem, R., Shuttleworth, W. J., Zreda, M., Franz, T. E., Zeng, X., and Kurc, S. A.: The Effect of Atmospheric Water Vapor on the Cosmic-ray Soil Moisture Signal, J. Hydrometeorol., 14, 16591671, doi:10.1175/JHM-D-12-0120.1, 2014.

Rosolem, R., Hoar, T., Arellano, A., Anderson, J. L., Shuttleworth, W. J., Zeng, X., and Franz, T. E.: Translating aboveground cosmic-ray neutron intensity to high-frequency soil moisture profiles at sub-kilometer scale, Hydrol. Earth Syst. Sci., 18, 4363 4379, doi:10.5194/hess-18-4363-2014, 2014.

Shangguan, W., Dai, Y., Duan, Q., Liu, B., and Yuan, H.: A global Soil Dataset for Earth System Modeling, J. Adv. Model Earth Syst., 6, 249-263, doi:10.1002/2013MS000293, 2014.

Shuttleworth, J., Rosolem, R., Zreda, M., and Franz, T.: The COsmic-ray Soil Moisture Interaction Code (COSMIC) for use in data assimilation, Hydrol. Earth Syst. Sci., 17, 3205-3217, doi:10.5194/hess-17-3205-2013, 2013.

Soil Survey Staff: Soil taxonomy: A basic system of soil classification for making and interpreting soil surveys, 2nd Edn., Natural Resources Conservation Service, US Department of Agriculture Handbook 436, available at: http://www.nrcs.usda.gov/ Internet/FSE_DOCUMENTS/nrcs142p2_051232.pdf (last access: 15 September 2016), 1999.

Suyker, A. E., Verma, S. B., Burba, G. G., and Arkebauer, T. J.: Gross Primary Production and Ecosystem Respiration of Irrigated Maize and Irrigated Soybean During a Growing Season, Agr. Forest Meteorol., 131, 180-190, 2005.

United Nations - United Nations Department of Economic and Social Affairs: World Population Prospects: The 2015 Revision, 2015.

United Nations - United Nations Food and Agriculture Organization: IUSS Working Group WRB, World Reference Base for Soil Resources 2006, first update 2007, World Soil Resources Reports No. 103, FAO, Rome, http://www.fao.org/fileadmin/templates/ nr/images/resources/pdf_documents/wrb2007_red.pdf, 2007.

Vachaud, G., Silans, A. P. D. E., Balabanis, P., Vauclin, M.: Temporal Stability of Spatially Measured Soil Water Probability Density Function, Soil Sci. Soc. Am. J., 49, 822-828, 1985.

Wood, E. F., Roundy, J. K., Troy, T. J., van Beek, L. P. H., Bierkens, M. F. P., Blyth, E., de Roo, A., Döll, P., Ek, M., Famiglietti, J., Gochis, D., van de Giesen, N., Houser, P., Jaffé, P. R., Kollet, S., Lehner, B., Lettenmaier, D. P., Peters-Lidard, C., Murugesu, S., Sheffield, J., Wade, A., and Whitehead, P.: Hyperresolution Global Land Surface Modeling: Meeting a Grand Challenge for Monitoring Earth's Terrestrial Water, Water Resour. Res., 47, W05301, doi:10.1029/2010WR010090, 2011.

Zreda, M., Desilets, D., Ferre, T. P. A., and Scott, R. L.: Measuring Soil Moisture Content Non-Invasively at Intermediate Spatial Scale Using Cosmic-Ray Neutrons, Geophys. Res. Lett., 35, L21402, doi:10.1029/2008g1035655, 2008.

Zreda, M., Shuttleworth, W. J., Zeng, X., Zweck, C., Desilets, D., Franz, T., and Rosolem, R.: COSMOS: the COsmic-ray Soil Moisture Observing System, Hydrol. Earth Syst. Sci., 16, 40794099, doi:10.5194/hess-16-4079-2012, 2012. 